\title{
The moral footprint of animal products
}

\author{
Krzysztof Saja
}

Accepted: 31 July 2012/Published online: 11 October 2012

(C) The Author(s) 2012. This article is published with open access at Springerlink.com

\begin{abstract}
Most ethical discussions about diet are focused on the justification of specific kinds of products rather than an individual assessment of the moral footprint of eating products of certain animal species. This way of thinking is represented in the typical division of four dietary attitudes. There are vegans, vegetarians, welfarists and ordinary meat-eaters. However, the common "all or nothing" discussions between meat-eaters, vegans and vegetarians bypass very important factors in assessing dietary habits. I argue that if we want to discover a properly assessed moral footprint of animal products, we should take into consideration not only life quality of animals during farming or violation of their rights - as is typically done-but, most of all, their body weight, life time in farms and time efficiency in animal products acquisition. Without these factors, an assessment of animal products is much too simplified. If we assume some easily accepted premises, we can justify a thesis that, regardless of the treatment of animals during farming and slaughtering, for example, eating chicken can be 163 times morally worse than eating beef, drinking milk can be 58 times morally better than eating eggs, and eating some types of fish can be even 501 times worse than eating beef. In order to justify such a thesis there is no need to reform common morality by, for example, criticizing its speciesism. The thesis that some animal products are much worse than others can be justified on common moral grounds.
\end{abstract}

K. Saja $(\square)$

Department of Philosophy, University of Szczecin, ul.

Krakowska 61/69, 71-017 Szczecin, Poland

e-mail: krzysztofsaja@gmail.com
Keywords Animals - Animal products - Animal welfarists · Animal rights - Ethics of killing · Vegetarianism $\cdot$ Veganism

\section{Introduction}

Most ethical discussions about diet are focused on the justification of specific kinds of products rather than on an individual moral assessment of eating products of certain animal species, which I refer to as the moral footprint of animal products. While many animal protectionists or abolitionists argue that at least people from developed countries should abandon meat eating or even the use of any animal products, their opponents criticize this claim and defend the common view of animals as producers of many goods for people. These ways of arguing are represented in the typical division into four dietary attitudes. There are vegans who refuse to use any animal products; vegetarians who do not accept eating any meat but consume other animal products such as eggs, milk, or honey; animal welfarists who do not condemn using animals, but try to minimize unnecessary suffering in farming; and the huge mass of ordinary people who eat without remorse everything permissible by law. However, these common "all or nothing" discussions between meat-eaters, vegans, and vegetarians bypass some very important factors in assessing dietary habits.

\section{What I argue and what I don't}

There are many philosophical disputes about the strength, justification, and content of animal rights. Animal activists and philosophers give different reasons why animals have 
moral status and should be treated properly. The most common and important justifications for abandoning or carefully selecting animal products lie in condemnation of unjustified killing of animals, using them merely as a means or causing suffering during farming. For these reasons, vegetarians refuse to eat meat and many animal welfarists fight for farming methods that increase respect for animal rights or their standard of life.

It is widely assumed that the animal well-being is an important moral factor. However, I argue that if we want to discover a properly assessed moral footprint of animal products, we need to take into consideration not only the life quality of animals during farming or violation of their rights - as is typically the case-but also their body weight and life duration in farms. If we consider such commonly neglected factors and assume some described in the next section premises, we can show that regardless of the treatment of animals during farming and slaughtering, for example eating $1 \mathrm{~kg}$ of chicken can be preliminarily 163 times morally worse than eating $1 \mathrm{~kg}$ of beef, drinking 1 average daily portion of milk can be 58 times morally better than eating 1 average daily portion of eggs, and eating $1 \mathrm{~kg}$ of carp can be 501 times worse than $1 \mathrm{~kg}$ of beef. Such conclusions undermine not only the common "all or nothing" discussion about animal products consumption, but also have very important practical implications for a state policy of minimizing animal harm, which I sketch later in the paper.

The thesis that animal products from some animal species are worse than others due to animal body weight and life duration in farms will be justified regardless of the reason for enhancing animal rights or the assumed ethics of killing. In order to broaden my argument, I show that my conclusions follow regardless of which particular ethics of protecting animals is considered. Therefore, I am not going to argue that one is sounder than any other. Instead, I present the argument in three different versions depending on the three most common answers to the question "What are the main reasons to stop using animal products?" These versions are entirely independent. In fact, I propose three different arguments of the same structure but treat them as one and explain jointly. Thus, for example, if we consider the first version of the argument we should take into account premises A1, B1, C, D1, E1, F1, the second version premises A2, B2, C, D2, E2, F2, and the third version premises $\mathrm{A} 3, \mathrm{~B} 3, \mathrm{C}, \mathrm{D} 3, \mathrm{E} 3, \mathrm{~F} 3$. It is important to remember that the premises with the same letter (e.g., A1, A2, A3) are not different expressions of one and the same claim but rather different claims that play the same role in the paper. To fully justify all of them individually is beyond my scope. Therefore, I will present only a basic argument for their validity. The main thesis of the paper is only a conceptual claim, mainly that if we assume such common premises we should accept that there are very important moral differences between animal products from different animal species due to animal body weight and life duration in farms.

\section{The philosophical premises of the argument}

The first important premise of the argument is the platitude of common morality and the minimal claim of all animal activists. Roughly speaking, it says that animals are not stones and for that reason they have at least some minimal rights. I hope that only someone who believes that animals do not have any moral rights or that their suffering or killing is morally irrelevant would not accept it. However, I do not know anybody who defends such a view. Most people (at least in the USA) admit that there are morally better and worse ways of treating animals. ${ }^{1}$ The common belief that animals should have at least some minimal moral protection can be specified in different ways due to different reasons for moral status of animals or badness of harming and killing. If someone believes that animals have at least the right not to be killed without a good reason, she should accept the first version of the argument and the following simple premise:

A1. It is morally wrong to kill sentient animals without important justification.

Different people can give different reasons to support the above claim. Many just think-especially non-philosophers-that unjustified killing is bad as a simple, intuitive, unanalyzable moral fact that does not need any further explanation or justification. This fact is sometimes stated in terms of a moral right to life: killing is bad for the same reason that it is bad to violate a right to life without important justification (e.g., self-defense). Some other people may claim that the badness of killing lies in the death that it brings. In this case, killing is wrong because it steals a life and cannot be analyzed or reduced to the loss of possible future goods or preferences satisfaction. Such a belief is sometimes associated with the thesis about the sanctity of life.

\footnotetext{
${ }^{1}$ In a 2004 survey conducted by researchers at The Ohio State University, $92 \%$ of Ohio residents agreed that it is important that farm animals are well cared for, and $81 \%$ said the well-being of farm animals is just as important as the well-being of pets (Rauch and Sharp 2005). Furthermore, $95 \%$ of respondents to a nationwide telephone survey conducted by Oklahoma State University agreed with the statement: "It is important to me that animals on farms are well cared for" (Lusk et al. 2007). In a 2005 survey of Michigan residents conducted by researchers at Michigan State University, $92 \%$ of respondents rated "humane animal treatment" as "very important" or "somewhat important" as a factor when purchasing animal products (Conner et al. 2008).
} 
The second version of the argument is based on a different type of ethics of killing because, even if we agree that it is morally wrong to kill sentient animals without important justification, we can give other reasons for that thesis. We can claim that the badness of killing depends not on any intrinsic evil of death or sanctity of life, but on deprivation of possible future goods or preventing satisfaction of future interests and preferences (Marquis 2007; McMahan 1988; Nagel 1970; Rachels 1986). In this version if we try to assess the moral footprint of animal products we need to assess the loss involved in the death of an animal from a certain species. This loss is determined by how many future goods are taken by killing an animal. If someone believes in such an ethics of killing, she should accept the second version of the argument and the second version of premise A:

A2. It is morally wrong to deprive animals of possible future goods without important justification.

The third version of the argument is presented for persons who do not believe that killing animals is prima facie bad. It corresponds with an assumption that the badness of animal products does not lie in animal death, but in harming animals through the bad conditions they experience before their death. For that reason in order to assess the moral footprint of animal products we have to be able to measure the quantity of harm (or benefit) done to animals during their lifetime. The most obvious types of harm are pain and suffering or unsatisfied preferences that are caused by farming (Singer 1977, 2006; Thomson 1990). The same version of the argument can be used if we believe that the wrongness done to animals lies in violating their rights not to be used as property (Francione 1995; Regan 1983). In order to assess this immoral usage we need to consider, as we also must when we are focused on suffering, the amount of time spent by animals in these harming conditions, and the quantity and quality of harm done during that time. However, because an aggregation of violations of rights may engender some problems, we will focus on suffering as the more common and less controversial reason to abandon eating animal products. If somebody thinks about the badness of animal products like animal welfarists ${ }^{2}$ or Peter Singer, she should accept the following premise:

\footnotetext{
2 The animal welfare position holds that there is nothing inherently wrong with using animals for human purposes, such as food, clothing, entertainment, and research, but that it should be done in a humane way that minimizes unnecessary pain and suffering. In the UK, the Farm Animal Welfare Council was set up by the government to act as an independent advisor on animal welfare in 1979 and expresses its policy as five freedoms: from hunger and thirst; from discomfort; from pain, injury, or disease; to express normal behavior; and from fear and distress.
}

A3. It is morally wrong to cause suffering to animals without important justification.

Every animal activist defends at least one of the above assumptions. However, there is no need to be a moral revisionist - as many animal protectionists are-to accept any of them. Most people agree that if we can minimize animal suffering or deaths and still achieve the objective of having plentiful, inexpensive food, then we should do it (Rauch and Sharp 2005; Lusk et al. 2007). Therefore, due to the different possible answers to what "without important justification" in these contexts could mean, I assume that most of us would accept at least one of the premises (A1, A2, or A3).

The second premise (premise B) is a statement of fact about the acquisition of animal products in most developed countries. B1 (B2) are important for the first two versions of the argument.

B1. (B2.) Breeding animals for food (meat, eggs, milk) causes them to be brought into existence and causes them to be killed.

It is not practically possible to eat meat without killing an animal. Although we can imagine farming methods for non-meat products (e.g., eggs and milk) in which people are not directly involved in breeding new animals or killing those that are not economically efficient enough, almost every animal-sourced food consumed in developed countries is produced in farming conditions in which people are responsible for animal life and death. If we did not produce meat, eggs, or milk, we would not bring to life and kill pigs, chickens, and dairy cows. Every kind of animal product is involved in death of respected animals directly or indirectly.

In the third version of the argument, which is focused on the well-being of animals, we should consider one other premise:

B3. Farming affects well-being of animals positively or negatively depending on the farming method and the time spent in farms.

In order to build the third version of the argument we need to assume that different farming methods have different effect on animal well-being, either positively or negatively (for the sake of simplicity I am not going to consider animals killed in the wild). Every type of farming for every animal species causes a different quality of life. On the one hand, many farmed animals, such as pigs, chickens, dairy cows, or fish in artificial tanks, are kept in Concentrated Animal Feeding Operations (CAFOs). The standard of their life in many CAFOs is probably lower than it would be in nature. Livestock is harmed by close confinement systems (cages, crates) or lifetime confinement in 
indoor sheds; discomfort and injuries caused by inappropriate flooring and housing; restriction or prevention of normal exercise and most natural foraging or exploratory behavior; restriction or prevention of natural maternal behavior; lack of daylight or fresh air and poor air quality in animal sheds; social stress and injuries caused by overcrowding; health problems caused by extreme selective breeding and management for fast growth and high productivity; reduced lifetime (longevity) of breeding animals (dairy cows, breeding sows); fast-spreading infections encouraged by crowding and stress in intensive conditions; de-beaking (beak amputation without pain killer) in the poultry and eggs industry to avoid pecking in overcrowded quarters; forced and overfeeding (by inserting tubes into the throats of ducks) in the production of foie gras, etc. On the other hand, some types of farming (e.g., extensive and ecological farming of beef cattle) can probably give a better standard of life than cattle could experience in the wild.

In addition to the above premises we also should assume that:

C. Bringing an animal into the world is not morally better than not bringing an animal into the world.

It could be said that farming animals for food is good for animals even if they suffer. Meat production gives animals life and without this production these animals would not exist at all. However, such a claim and its implications are quite odd because comparing existence with non-existence produces many philosophical problems that it would be better to omit here. Moreover, even if causing an animal to exist can benefit that animal, nothing follows about the permissibility of killing it or causing it to suffer once it exists. First, causing an animal to exist benefits it only if its life is worth living, which arguably is not always the case for animals that are kept in CAFOs. Second, causing an animal to exist might entail a responsibility to care for it, not a permission to kill it. Third, once an animal exists, it may have rights that protect it, independently of how it came to exist. Fourth, it may be that once an animal exists, its interest in continuing to live outweighs any human interest that might be served by killing it. The weighing of interests seems independent of how the animal came into existence. In short, premise $\mathrm{C}$ is a stronger claim than I need in the argument. My argument should be persuasive even to most of those who deny premise $\mathrm{C}$ because of the considerations I have just noted. ${ }^{3}$

A fourth important premise (premise D) can be roughly stated as the claim that the quantity of victims matters morally. Its validity depends on accepting premise A, because if somebody does not believe that killing

\footnotetext{
3 The above remarks about premise $\mathrm{C}$ I owe to a private conversation with Jeff McMahan.
}

or harming animals without important justification is immoral, she will not agree with premise D either.

If we admit that what makes animal products morally bad is a badness of killing animals (A1), which is the obvious precursor of eating meat and, most often, also a consequence of the production of eggs and milk, we need to assume the following premise:

D1. It is $N$ times morally worse to kill $n$ times more sentient animals (if everything else remains the same).

If we believe in the second reason for protecting animals (A2) and therefore focus on the second version of the argument, we need to accept:

D2. It is $N$ times morally worse to deprive $n$ times more possible future goods (if everything else remains the same).

The last version of premise $\mathrm{D}$ for the third version of the argument is focused on suffering or harm during farming:

D3. It is $N$ times morally worse to cause $n$ times more suffering (if everything else remains the same).

Let us imagine three cases in which you have only two options and everything else remains the same: to let 2 or 3 people die; to let 3 or 4 people die; to let 4 or 10 people die. The above premises assume that the first options are morally better and letting more rather than fewer people die is worse. If everything else remains the same, and the only thing that can be changed is the duration of feeling pain, the better option is to feel pain for as short a time as possible. The same holds true for animals. If we can test some medical research with an option that kills fewer laboratory rabbits and everything else remains the same we ought to take that option. Fewer total deaths and loss of possible future goods or pain are better than more. For every person who accepts an utilitarian ethics, the above thesis has to be perfectly obvious. In addition, most nonconsequentialists would agree that if everything else remains the same, numbers morally count. On the other hand, anybody who would claim that numbers do not morally count will not accept my argument. However, only a few philosophers would defend such a view about people (Taurek 1977; Timmermann 2004) and it would be even more uncommon to claim this about animals.

The last conceptual premise (E) is important to allow cross-species moral comparisons. The formal structure of its more detailed versions (E1-E3) is:

E. The badness of killing or causing suffering to an animal from species $a$ is $m$ times as much as the badness of killing or causing suffering to an animal from species $b$.

Not every animal has the same right to life and the killing of any of them is not equally bad. Most people have 
different attitudes toward killing parasites, pests, livestock, wild animals under protection, or pets. In Poland people much more value the lives of cats and dogs than those of pigs, chickens, and cows. We do not kill homeless domestic animals, but put them in an animal shelter. Nevertheless, we are very merciless to rats and mosquitoes. We do not think that the death of every compared animal species is equally bad. Moreover, there are natural differences in animal bodies and psychology. As Jeff McMahan (2002) argues, psychological capacity is related to the degree of psychological (prudential) unity within a life and that psychological unity is relevant to the assessment of the harm or loss involved in death. This psychological capacity is also relevant to an animal's capacity for well-being. Some animals are capable of much higher levels of well-being than others are capable of. Even if fish can feel pain their lost future goods are less valuable than the future goods of killed pigs, as the life of cognitively more developed animals is richer, more worth living, and worse to be shortened. Additionally, not every species has the same capability to feel pain. The nervous system of fish is not as developed as that of cows, so they could not be harmed as much by farming as cows. It can be argued that carp living in crowded tanks suffer less than pigs living alone in small steel and concrete cages. Similar treating of different animal species can produce different amounts of harm.

The premise $\mathrm{E}$ and the above reservations show that to make a final and detailed comparison of the moral footprint of animal products, we would need to collect a lot of empirical data about the compared animals' psychology, physiology, and farming condition in order to assess the proper amount of harm caused by killing or farming condition of animals from different species. This is beyond the scope of this paper. However, in order to justify the thesis of the article that the ethics of consuming animal products ought to consider not just animal harm but also other factors such as animal body weight or life duration in farms, then initially we need to ignore these differences and for the sake of simplicity assume that killing or harming animals of different species is important equally. For that reason let us assume that (accordingly to the version of the argument):

E1. The death of every farmed animal is equally bad.

E2. For every farmed animal in an equal period of time of being dead the quantity and value of a loss of possible goods are equal.

E3. For every farmed animal in an equal period of time the quantity and quality of suffering are equal.

The premises E1-E3 are inconsequential. However, if we assume them for a moment we can later show that even if we know the relative physiological capacity of animals to feel pain and the real amount of harm or benefit caused by farming, this will not override the more important factors in assessing moral footprint of animal products such as animal body weight or longevity in farms. If we accept E1E3 we will be able to see that animal capacity of wellbeing, amount of suffering, and harm is not as important as it is commonly believed.

\section{Commonly missed facts about animal products}

In order to show that there are preliminarily very large differences in the moral footprint of animal products from different animal species, it is important to take into consideration some other factors that are commonly missing in discussions about the ethics of diet. They are factual in nature and represent morally important statistical data about the farming and consumption of animals for food. In the following discussion I will rely on typical Polish practices of production and consumption of animal products such as beef, pork, chicken, carp (a traditional Christmas Eve fish in Poland), eggs, and milk. According to statistical data the average Pole consumes approximately $70 \mathrm{~kg}$ (154 lbs) of different meat products per year, but mostly from cattle, pigs, chicken, and fish. They also eat 200 eggs and drink $190 \mathrm{~kg}$ (418 lbs) of milk per year. ${ }^{4}$

If we want to assess and compare how much aggregate harm would be done to animals of certain species during an average 70 years of consumption by one person, it is useful to ignore the fact that meat eaters consume different kinds of meat products from different species. Therefore, for the sake of argument I will investigate how much aggregate harm would be done to animals of certain species if a typical meat-eater were to eat animal products from only one species for all of his or her life. The moral footprint of animal products depends also on the assumed reason for the badness of using animals. If the harm is caused by taking life or bringing death (A1), then according to premise D1 it would be $n$ times morally worse to kill $n$ times more animals of some kind. In this respect to assess the moral footprint of animal products we should include the quantity of animal deaths. In order to do this we need to know the average amount of animal products (meat, eggs, milk) per one animal. The important numbers are in Table 1.

If one would consume only the meat of a single species, the aggregate quantity of killed animals per 70 years of consumption would vary a lot due to the weight of each killed animal. If someone would eat only beef they would be responsible for the deaths of 15 animals, but if they were to consume only chicken or carp, then they would be responsible for the deaths of 2,450 or 3,220 animals respectively.

\footnotetext{
${ }^{4}$ All statistical data in this article are from the Polish Central Statistical Office (2010).
} 
Table 1 Calculus of animal deaths

\begin{tabular}{|c|c|c|c|c|c|c|}
\hline & $\begin{array}{l}\text { Beef (beef } \\
\text { cattle) }\end{array}$ & $\begin{array}{l}\text { Pork } \\
\text { (pigs) }\end{array}$ & $\begin{array}{l}\text { Poultry } \\
\text { (chickens) }\end{array}$ & $\begin{array}{l}\text { Fish } \\
\text { (carps) }\end{array}$ & Eggs & Milk \\
\hline (a) Average animal products per one animal life & $\begin{array}{l}320 \mathrm{~kg} \\
\quad(704 \mathrm{lbs})\end{array}$ & $\begin{array}{l}100 \mathrm{~kg} \\
\quad(220 \mathrm{lbs})\end{array}$ & $\begin{array}{l}2 \mathrm{~kg} \\
\quad(4.4 \mathrm{lbs})\end{array}$ & $\begin{array}{l}1.5 \mathrm{~kg} \\
\quad(3.3 \mathrm{lbs})\end{array}$ & 200 eggs & $21,000 \mathrm{~kg}(46,200 \mathrm{lbs})$ \\
\hline $\begin{array}{l}\text { (b) Quantity of killed animals of certain species } \\
\text { to satisfy average animal products intake by } 1 \\
\text { person in } 1 \text { year }[70 \mathrm{~kg}(154 \mathrm{lbs})] \text {, who would } \\
\text { consume only the product of a certain species } \\
\text { (a / } 70 \mathrm{~kg})\end{array}$ & 0.22 lives & 0.7 lives & 35 lives & 46 lives & $\begin{array}{l}2 \text { lives* } \\
\text { (assumed } 200 \\
\text { eggs } \\
\text { consumed per } \\
\text { year) }\end{array}$ & $\begin{array}{l}0.036 \text { lives** (assumed } \\
190 \mathrm{~kg}(418 \mathrm{lbs}) \text { of } \\
\text { milk consumed per } \\
\text { year) }\end{array}$ \\
\hline $\begin{array}{l}\text { (c) Quantity of killed animals per average time } \\
\text { of consumption ( } 70 \text { years), if one would } \\
\text { consume only the product of single species } \\
\text { (b } \times 70 \text { years })\end{array}$ & 15 lives & 49 lives & $\begin{array}{l}2,450 \\
\text { lives }\end{array}$ & $\begin{array}{l}3,220 \\
\text { lives }\end{array}$ & 140 lives & 2.5 lives \\
\hline
\end{tabular}

All statistical data are from the Polish Central Statistical Office (2010)

* One typical hen produces 200 eggs per year and lives in a farm for about 12 months. Therefore, the average consumer of eggs, who eats 200 eggs per year, is responsible for the death of 1 hen and the death of 1 male chick (cocks do not give eggs, therefore, male chicks are typically killed right after their birth)

** The amount of 0.036 cows killed per year is assessed on the assumption that the average consumption of milk per year is $190 \mathrm{~kg}$ per person, which is the typical amount in Poland. This would give 0.009 killed cows per year of average milk consumption. However, in modern dairy farms cows are inseminated about 3 times per life for better efficiency in milk production; therefore, typical byproduct of milk acquisition are 3 calves per dairy cow. For that reason the amount of 0.036 cattle killed per 1 year of typical milk consumption is a product of killed cows ( 0.009$)$ and their three calves $(3 \times 0.009$ calves $)(0.009$ cow $+(3 \times 0.009$ calves $)=0.036$ cattle per 1 year. $)$

If we think that the wrongness of killing lies in the deprivation of possible future goods or preventing of satisfaction of future interests (A2), in order to construct the moral footprint of animal products we should take into consideration not only the quantity of animal deaths, but also how many years of life we take away from them for certain products. The important numbers are in Table 2.

Even if the badness of killing lies in depriving possible future goods, the important differences between animal products from different species are similar to that from Table 1. We can estimate that 70 years of eating carp would cost 135,240 aggregate years of life in comparison to 710 years of life when consuming pork.

If we are focused on the third version of the argument and believe that what is morally bad about animal products is causing animals to suffer (A3), then an important factor for assessing the moral footprint of animal products would be the aggregate product of quality of life and period of suffering in farming. If the harm lies in violating their rights not to be used or enslaved without important justification, then crucial would be the aggregate product of the level of injustice and time period of wrongdoing. In either case the time spent in farms would have a significant impact. Therefore, global well-being or wrongdoing in farms depends not only on the assumed quality of life or level of injustice, but mostly on the average farming time and the quantity of killed animals. The huge impact of these factors can be shown in Table 3 .

All of this can be summarized in Table 4, in which we compare the important consequences of eating $70 \mathrm{~kg}$ (154 lbs) of meat per year by one person who would consume only products from one species.

If we assume the consumption of eggs and milk as equal to the average consumption in Poland (200 eggs per year and $190 \mathrm{~kg}$ milk per year), we can show in Table 5 preliminary consequences of 70 years of consuming typical amounts of eggs and milk.

Another step in the argument requires some computed data from the above tables, i.e. assessments of the disproportion between the consequences of farming animals from different species. This data will vary depending on the version of the argument and the compared animal species. We can propose the following factual estimations:

F1. Eating chicken in aggregate kills 163 times more animals than eating beef. ${ }^{5}$

F2. Farming carp in aggregate takes away 501 times more animal possible future goods than farming cattle for beef. ${ }^{6}$ F3. Farmed carp in aggregate suffer 358 times longer than farmed beef cattle. ${ }^{7}$

\footnotetext{
5 The number 163 is equal to the quantity of killed chickens from Table 4 row (c) divided by the quantity of killed beef cattle $(2,450 /$ $15=163)$.

6 The number 501 is equal to the quantity of the aggregate years of shorten lifespan of carps from Table 4 row (g) divided by the quantity of aggregate years of shortened lifespan of beef cattle $(135,240 /$ $270=501)$.

7 The number 358 is equal to the quantity of aggregate period of suffering of carps from Table 4 row (h) divided by the quantity of aggregate period of animal suffering of beef cattle $(10,733$ / $30=358)$.
} 
Table 2 Calculus of taken animals' possible future goods

\begin{tabular}{|c|c|c|c|c|c|c|}
\hline & $\begin{array}{l}\text { Beef } \\
\text { (beef } \\
\text { cattle) }\end{array}$ & $\begin{array}{l}\text { Pork } \\
\text { (pigs) }\end{array}$ & $\begin{array}{l}\text { Poultry } \\
\text { (chickens) }\end{array}$ & $\begin{array}{l}\text { Fish } \\
\text { (carps) }\end{array}$ & Eggs & Milk \\
\hline $\begin{array}{l}\text { (c) Quantity of killed animals per average human time of consumption ( } 70 \text { years), if } \\
\text { one would consume only the product of a single species }\end{array}$ & 15 & 49 & 2,450 & 3,220 & 140 & 2.5 \\
\hline (d) Average animal lifespan in farms (months) & 24 & 6 & 4.5 & 40 & $6^{*}$ & $30 * *$ \\
\hline (e) Normal average lifespan, if animals would not be killed (years) & 20 & 15 & 10 & 45 & 10 & 20 \\
\hline (f) Years of shortened lifespan of one animal by killing it $(e-d)$ & 18 & 14.5 & 9.5 & 42 & 9.5 & 17.5 \\
\hline $\begin{array}{l}\text { (g) Aggregate years of shortened lifespan by killing animals during } 70 \text { years of } \\
\text { animal product consumption }(c \times f)\end{array}$ & 270 & 710 & 23,275 & 135,240 & 1,330 & 43.8 \\
\hline
\end{tabular}

* An average hen lives on a farm for 1 year and male chicks are killed after their birth. Therefore, average animal lifetime in egg production is 0.5 years

** An average dairy cow lives on a farm for 4 years. However, it breeds 3 calves, which live 2 years on average. Therefore, I estimate that the average lifetime of cattle on dairy farms is 2.5 years

Table 3 Calculus of animal suffering in farming

\begin{tabular}{|c|c|c|c|c|c|c|}
\hline & $\begin{array}{l}\text { Beef } \\
\text { (beef } \\
\text { cattle) }\end{array}$ & $\begin{array}{l}\text { Pork } \\
\text { (pigs) }\end{array}$ & $\begin{array}{l}\text { Poultry } \\
\text { (chickens) }\end{array}$ & $\begin{array}{l}\text { Fish } \\
\text { (carps) }\end{array}$ & Eggs & Milk \\
\hline $\begin{array}{l}\text { (c) Quantity of killed animals per average human time of consumption } \\
\text { (70 years), if one would consume only the product of a single species }\end{array}$ & 15 lives & $\begin{array}{l}49 \\
\text { lives }\end{array}$ & $\begin{array}{l}2,450 \\
\text { lives }\end{array}$ & $\begin{array}{l}3,220 \\
\text { lives }\end{array}$ & $\begin{array}{l}140 \\
\text { lives }\end{array}$ & $\begin{array}{l}2.5 \\
\text { lives }\end{array}$ \\
\hline (d) Average animal lifespan in farms (months) & 24 & 6 & 4.5 & 40 & 6 & 30 \\
\hline $\begin{array}{l}\text { (h) Aggregate time of farming animals per average human } \\
\text { lifetime }(c \times d) \text { (years) }\end{array}$ & 30 & 25 & 919 & 10,733 & 70 & 6.3 \\
\hline $\begin{array}{l}\text { (i) Global well-being of animals in farming if we assume the same } \\
\text { quality of life of different species }(-1 \times \mathrm{h})\end{array}$ & -30 & -25 & -919 & $-10,733$ & -70 & -6.3 \\
\hline
\end{tabular}

Table 4 Important consequences of meat consumption

\begin{tabular}{lcll}
\hline $\begin{array}{l}\text { Animal } \\
\text { products }\end{array}$ & $\begin{array}{l}\text { Killed animals } \\
\text { for one person } \\
\text { per 70 years of } \\
\text { animal product } \\
\text { consumption (c) }\end{array}$ & $\begin{array}{l}\text { Aggregate years } \\
\text { of shortened } \\
\text { lifespan by killing } \\
\text { animals during } \\
70 \text { years of } \\
\text { animal product } \\
\text { consumption } \\
\text { (g) (years) }\end{array}$ & $\begin{array}{l}\text { Aggregate } \\
\text { average period of } \\
\text { animal suffering } \\
\text { during 70 years of } \\
\text { consumption } \\
\text { (h) (years) }\end{array}$ \\
\hline Beef & 15 & 270 & 30 \\
Pork & 49 & 710 & 25 \\
Chicken & 2,450 & 23,275 & 919 \\
Carp & 3,220 & 135,240 & 10,733 \\
\hline
\end{tabular}

\section{The argument}

If we choose one version of the argument and take for granted all premises $\mathrm{A}$ to $\mathrm{F}$, we can reconstruct it in few simple steps. Its different versions, which depend on the different philosophies of the badness of killing or using animals, could be presented by changing the numbers of the appropriate premises of the argument. If we think that animals have at least the right not to be killed without a
Table 5 Important consequences of non-meat animal products

\begin{tabular}{llll}
\hline $\begin{array}{l}\text { Animal } \\
\text { products }\end{array}$ & $\begin{array}{l}\text { Killed animals for } \\
\text { one person per } \\
70 \text { years of } \\
\text { average amount } \\
\text { of consumption } \\
\text { (c) }\end{array}$ & $\begin{array}{l}\text { Aggregate years } \\
\text { of shortened } \\
\text { lifespan by } \\
\text { killing animals } \\
\text { during 70 years } \\
\text { of average } \\
\text { amount of } \\
\text { consumption } \\
\text { (g) (years) }\end{array}$ & $\begin{array}{l}\text { Aggregate period } \\
\text { of animal } \\
\text { suffering during } \\
70 \text { years of } \\
\text { average amount } \\
\text { of consumption } \\
\text { (h) (years) }\end{array}$ \\
\hline Eggs* & 140 & 1,330 & 70 \\
Milk & 2.5 & 43.8 & 6.3 \\
\hline
\end{tabular}

* The above comparison assumes the typical way of acquiring animal products in Poland. We can of course imagine a vegetarian who eats eggs bought from ecological farms where male chicks are not killed and live with hens until natural death. Such eggs do not cost 2 bird lives per year. But most eggs eaten do. The same is true for other animal products

good reason, we can show the argument in the following way:

A1. It is morally wrong to kill sentient animals without important justification. 
Table 6 Preliminary comparison of the moral footprint of animal products*

\begin{tabular}{|c|c|c|c|}
\hline \multirow[t]{2}{*}{ Preliminary comparison of two animal products } & \multicolumn{3}{|c|}{$\begin{array}{l}\text { How many times one unit of animal product is preliminarily worse than a second one due to } \\
\text { different factors of badness of animal production (killing, taken future goods, suffering in } \\
\text { farming) }\end{array}$} \\
\hline & Death/killing (c) & Loss of future (e) & Suffering in farming (h) \\
\hline Carp to beef ( $\mathrm{n}$ times worse) & 214 & 501 & 358 \\
\hline Chicken to beef (n times worse) & 163 & 86 & 30 \\
\hline Pork to beef ( $\mathrm{n}$ times worse) & 3 & 0.4 & 0.8 \\
\hline Chicken to pork (n times worse) & 50 & 107 & 37 \\
\hline Eggs to beef ( $\mathrm{n}$ times worse) & 9 & 10 & 2 \\
\hline Eggs to pork (n times worse) & 3 & 12 & 3 \\
\hline Eggs to milk (n times worse) & 56 & 30 & 11 \\
\hline
\end{tabular}

* All of the numbers in Table 6 were computed as described in Footnotes 5-7

B1. Breeding animals for food (meat, eggs, milk) causes them to be brought into existence and to be killed.

C. Bringing an animal into the world is not morally better than not bringing an animal into the world.

D1. It is $N$ times morally worse to kill $n$ times more sentient animals (if everything else remains the same).

E1. The death of every farmed animal is equally bad.

F1. Eating chicken in aggregate kills 163 times more animals than eating beef.

Therefore, eating chicken is preliminarily 163 times morally worse than eating beef.

If we think that the moral significance lies not in animal deaths, but in the suffering in farming, the reconstructed argument would be the following:

A3. It is morally wrong to cause suffering to animals without important justification.

B3. Farming affects well-being of animals positively or negatively depending on the farming method and the time spent in farms.

C. Bringing an animal into the world is not morally better than not bringing an animal into the world.

D3 It is $N$ times morally worse to cause $n$ times more suffering (if everything else remains the same).

E3. For every farmed animal in an equal period of time the quantity and quality of suffering are equal.

F3. Farmed carp in the aggregate suffer 358 times longer than farmed cattle for beef.

Therefore, eating carp is preliminarily 358 times morally worse than eating beef.

The second version of the argument can be constructed in a similar fashion. The conclusions, which are comparative judgments about the preliminary badness of some specified unit of different animal products (for example 1 kilogram), can be presented in one simple table. In the rows of Table 6 different animal products are compared by asking how many times one unit of a product is preliminarily worse than another. The results are divided into three columns according to three different factors of animal products badness: the first shows how many times one product is preliminarily worse than another according to the quantity of deaths, the second is according to preventing future goods, and the third is according to the suffering in farms or violating the right not to be treated as property. If we accept premises $\mathrm{A} 1-\mathrm{F} 1$, the table shows that, for example, eating $1 \mathrm{~kg}$ of carp is 214 times morally worse than eating $1 \mathrm{~kg}$ of beef, $1 \mathrm{~kg}$ of chicken is 50 times worse than $1 \mathrm{~kg}$ of pork, and 1 average daily egg ration is 56 times worse than 1 typical daily milk ration.

In the light of the above data we can fully answer the question about the validity of premises E1-E3. Now it can be seen that the disproportions of the preliminary badness of one unit of animal product of different species (for example 1 kilogram of meat or one average daily ration of milk or eggs) presented in Table 6 are much bigger than the presumptive cognitive or moral diversities of different species. Even if there is some disproportion about the right to life, degree of psychological unity within a life, capability of suffering, or farming conditions of different species, it would be very odd to claim that, for example, fish suffer 300 times less than cattle in the equal period of time or that a chicken's life is morally worth 50 times less than a pig's life. Even if we agreed that the life of a fish is, for example, 10 times less valuable than that of a pig because fish are 10 times less cognitively developed and can feel 10 times less pain accordingly, it would still not be enough to make the claim that eating $1 \mathrm{~kg}$ of fish is as bad as eating $1 \mathrm{~kg}$ of pork. The preliminary differences of the moral footprint of meat from carps and pigs are much bigger than 10 and they seem bigger than any cognitive disproportion between the compared vertebrates. If someone wants to prove that, for example, eating $1 \mathrm{~kg}$ of carp is morally equal to eating $1 \mathrm{~kg}$ of beef or pork because carp suffer less, they would have to show accordingly that, for 
example, carp are at least 358 times less capable of suffering than beef cattle. And this is probably false. If someone would claim that eating $1 \mathrm{~kg}$ of chicken is not worse than eating $1 \mathrm{~kg}$ of pork because pigs can have richer and more valuable future lives than chickens, then they would have to prove that a pig's future life is richer or more valuable at least 107 times more than a chickens. This seems false as well. Speaking more formally, if we would claim that despite the data from Table 6 the eating of one unit of animal product (e.g., meat, eggs or milk) is not worse than the eating of another product (e.g., pork or beef) because of $x$ (e.g., cognitive abilities and degree of psychological unity within a life of animals), we have to prove that factor $x$ differentiates animal species at least as much as is showed in Table 6. However, because morally significant aggregate body weight and lifespan of animals of different species can differ by a factor of a hundred or more, there is only a very low probability that other morally important factors would be able to overbalance them.

\section{Important implications}

The thesis that animal body weight and life duration in farms are significant but commonly neglected moral features has important practical implications. First of all, if someone tries to minimize the harm done to animals caused by producing food from them, they should consider not only supporting farming methods that increase respect for animal rights or their standard of life-as it is typically the casebut, first of all, try to promote eating beef and pork rather than chicken and fish. If minimizing harm to animals would be our aim, a much bigger impact could be achieved not by consuming only ecological, low-suffering animal products, but mostly by choosing products from bigger animals like beef cattle. Despite the strangeness of such a conclusion, choosing and promoting big body weight and efficient animal products is the most rational way of minimizing animal harm (except by being a vegan). If we would eat only meat from such animals we would prevent much more pain, death, or loss of possible future goods than by trying to consume, for example, well-farmed chickens. Even if the quality of life in farming is important, more important is animal weight and farming time. Moreover, the traditional division of diets made by food products types (vegetable, meat, non-meat animal products) is irrelevant from the ethical point of view. Not well-informed vegetarians who eat eggs produced in CAFOs can cause much more animal harm than a person who eats only red meat without eggs. Drinking milk could be much less harmful than eating eggs. Promoting "white meat" (poultry, fish) can be more wrong than promoting a normal meat diet. If someone cannot abandon meat eating, maybe the best ethical option would be to consume beef. The same is true for welfarist meat-eaters who accept common morality, believe in anthropocentrism in ethics, but think that animals have some minimal rights. If we can fulfill our dietary aims of eating meat without increasing unjustified or unnecessary animal deaths and suffering, we should do that. Everybody who accepts that mere diversity of animal products on our plates does not justify, for example, 300 times more animal deaths or suffering should change their diet.

Most philosophers or animal activists, who try to change our common morality of using animals for consumption, focus on violating animal rights or the bad conditions in farming. Many developed countries try to legally restrict some harmful forms of treating animals such as long transportation for slaughter without stops, battery cages for egg-laying hens, de-beaking of chickens, confinement of sows during pregnancy and for most of their adult life, and slaughtering animals without stunning them beforehand. However, if we want to reduce animal harm, then there are more important factors than the quality of life of livestock that should be taken into consideration. If my argument is correct and we want to construct a detailed moral footprint of animal products, then we should take into account not only life quality (preference satisfactions) during farming and violation of animal rights, but, first and foremost, animal body weight and lifetime animals spend in farms.

Acknowledgments I would like to extend a note of gratitude to Renata Pilarczyk, Jeff McMahan, Harvey S. James, Adriana Schetz, Urszula Zarosa, and anonymous reviewers from Agriculture and Human Values for their very helpful and valuable comments.

Open Access This article is distributed under the terms of the Creative Commons Attribution License which permits any use, distribution, and reproduction in any medium, provided the original author(s) and the source are credited.

\section{References}

Central Statistical Office. 2010. Statistical Yearbook of Agriculture, Warsaw: Zaklad Wydawnictw Statystycznych. http://www.stat. gov.pl/gus/5840_4127_PLK_HTML.htm. Accessed 26 July 2012.

Conner, D.S., V. Campbell-Arvai, and M.W. Hamm. 2008. Consumer preferences for pasture-raised animal products: results from Michigan. Journal of Food Distribution Research 39(2): 12-25.

Francione, G.L. 1995. Animals, property, and the law. Philadelphia: Temple University Press.

Lusk, J.L., F.B. Norwood, and R.W. Prickett. 2007. Consumer preferences for farm animal welfare: results of a nationwide telephone survey. Department of Agricultural Economics, Oklahoma State University. http://asp.okstate.edu/baileynorwood/ Survey4/files/InitialReporttoAFB.pdf. Accessed 26 July 2012.

Marquis, D. 2007. An argument that abortion is wrong. In Ethical theory: An anthology, ed. R. Shafer-Landau, 439-450. Oxford: Blackwell.

McMahan, J. 1988. Death and the value of life. Ethics 99(1): 32-61. 
McMahan, J. 2002. The ethics of killing: Problems at the margins of life. New York: Oxford University Press.

Nagel, T. 1970. Death. Noûs 4(1): 73-80.

Rachels, J. 1986. The end of life: Euthanasia and morality. Oxford: Oxford University Press.

Rauch, A., and J.S. Sharp. 2005. Ohioans' attitudes about animal welfare. A topical report from the 2004 Ohio Survey of Food, Agricultural and Environmental Issues. Columbus, $\mathrm{OH}$ : Social Responsibility Initiative, Department of Human and Community Resource Development, The Ohio State University. http://ohio survey.osu.edu/pdf/2004_Animal_report.pdf. Accessed 26 July 2012.

Regan, T. 1983. The case for animal rights. Berkeley: University of California Press.

Singer, P. 1977. Animal liberation. New York: Avon Books.

Singer, P. (ed.). 2006. In defense of animals: The second wave. Oxford: Blackwell.
Taurek, J.M. 1977. Should the numbers count? Philosophy and Public Affairs 6(4): 293-316.

Thomson, J. 1990. The realm of rights. Cambridge: Harvard University Press.

Timmermann, J. 2004. The individualist lottery: how people count, but not their numbers. Analysis 64(282): 106-112.

\section{Author Biography}

Krzysztof Saja is an assistant professor in the Department of Philosophy at the University of Szczecin in Poland. 